\title{
Pemberdayaan Kelompok Nelayan Desa Arakan Kabupaten Minahasa Selatan Dalam Diversifikasi Produk Olahan Ikan
}

\author{
(Empowerment of Fisherman Groups in Arakan Village, South Minahasa Regency in \\ Diversifying Processed Fish Products)
}

\author{
Helen Jenny Lohoo*, Joyce Christiana Valencia Palenewen
}

Staf Pengajar Program Studi Budidaya Perairan, FPIK UNSRAT Manado

Penulis korespondensi: Helen Loho; helen_lohoo@unsrat.ac.id

\begin{abstract}
S
The purpose of this program is to empower the Women Fishermen group in Arakan Village, South Minahasa Regency, North Sulawesi Province in processing / diversifying fish products into shredded. This diversification of shredded fish is expected to increase production, management to be skilled and economically independent which in turn can increase people's income. The specific target of this activity is to produce shredded fish products that are superior in terms of taste, sanitation and hygiene, durability, and create jobs / businesses and strong management. The implementation methods applied to this program are 1) the production of shredded fish; 2) Approach methods to overcome partner problems, namely counseling, training, mentoring and evaluation; 3 ) Work procedures to support aspects of the problem, respectively, namely survey, counseling, training, evaluation, output, reporting.

The result of this activity is an increase in the skills and knowledge or empowerment of the Women Fishermen group in Arakan Village, South Minahasa Regency, North Sulawesi Province in processing/diversifying fishery products, namely fish floss which is delicious and favored by panelists, packaged practically. This activity is expected; women in coastal areas can be empowered through economic activities based on fishery business so that they become a new locomotive in bringing the economy of fishing communities to be better.
\end{abstract}

Keywords: empowerment, diversifying processed, fish products, Arakan village

\begin{abstract}
ABSTRAK
Tujuan program ini yaitu memberdayakan kelompok Wanita Nelayan Desa Arakan Kabupaten Minahasa Selatan Provinsi Sulawesi Utara dalam mengolah /diversifikasi produk ikan menjadi abon. Adanya diversifikasi olahan abon ikan ini diharapkan dapat meningkatan produksi, manajemen agar trampil dan mandiri secara ekonomi yang pada akhirnya dapat meningkatkan pendapatan masyarakat.Target khusus kegiatan ini menghasilkan produk abon ikan yang unggul dari segi rasa, sanitasi dan higiene, daya awet, dan menciptakan lapangan pekerjaan / usaha dan manajemen yang tangguh. Metode pelaksanaan yang diterapkan pada program ini yaitu 1) produksi abon ikan; 2) Metode pendekatan untuk mengatasi persoalan mitra yakni penyuluhan, pelatihan, pendampingan dan evaluasi; 3) Prosedur kerja untuk mendukung aspek permasalahan, berturut-turut yaitu survey, penyuluhan, pelatihan, evaluasi, luaran, pelaporan. Hasil dari kegiatan ini adalah peningkatan skill dan pengetahuan atau keberdayaan kelompok Wanita Nelayan Desa Arakan Kabupaten Minahasa Selatan Provinsi Sulawesi Utara dalam pengolahan/diversifikasi produk hasil perikanan yaitu abon ikan yang enak dan disukai panelis, dikemas praktis.Adanya kegiatan ini diharapkan kaum wanita yang ada di daerah pesisir dapat diberdayakan melalui kegiatan ekonomi yang berbasis usaha perikanan sehingga menjadi lokomotif baru dalam membawa ekonomi masyarakat nelayan yang lebih baik.
\end{abstract}

Kata kunci: Pemberdayaan, diversifikasi, produk olahan ikan, desa Arakan 


\section{PENDAHULUAN}

\section{Analisis Situasi}

Kabupaten Minahasa Selatan memiliki wilayah pesisir dengan panjang garis pantai $\pm 168,22 \mathrm{~km}$ dan luas laut 56.000 ha $(4 \mathrm{mil})$, mempunyai potensi sumberdaya kelautan dan perikanan yang dapat dikembangkan dan dapat meningkatkan pendapatan ekonomi masyarakat. Selain potensial untuk budidaya perikanan laut, penangkapan ikan, juga memiliki panorama yang indah sehingga dapat dikembangkan untuk pariwisata.

Desa Arakan merupakan salah satu Desa Penyangga di bagian selatan Taman Nasional Bunaken. Desa dengan masyarakat yang bermukim Suku Bajo menjadi salah satu desa sentra utama perikanan di Kabupaten Minahasa Selatan terutama sebagai sentra budidaya rumput laut.

Dalam menghadapi ketidakpastian lingkungan laut, berbagai usaha dilakukan oleh nelayan untuk beradaptasi. Dengan ketidakberdayaan yang dialami,maka para nelayan berupaya untuk selalu meningkatkan pendapatannya. Berbagai cara yang ditempuhantara lain adalah berusaha untuk meningkatkan hasil tangkapan yang lebih banyak dan yang gmempunyai nilai ekonomi tinggi, serta mencari peluang pasar yang lebih menguntungkan atau dengan melakukan penangkapan ke daerah penangkapan yang jauh dari daerah tempat tinggal mereka.

$$
\text { Lingkungan fisik nelayan }
$$
mempunyai karakteristik yang berbeda dengan petani. Sumberdaya perikanan mempunyai sifat sulit diramal serta sasaran target operasi penangkapannya hidup dan liar. Hal ini membuat usaha perikanan mempunyai resiko kerusakan dan kerugian yang tinggi serta pola pendapatan yang fluktuatif. Kenyataan tersebut memberikan dampak bagi desa pesisir yaitu kemiskinan. Sumber daya pesisir atau laut dengan produktifitas yang tinggi diharapkan berperan penting dalam mengatasi kemiskinan.

Sektor kelautan dan perikanan menjadi salah satu program prioritas pembangunan daerah. Karena ini menjadi prioritas guna mewujudkan kedaulatan pangan dalam menunjang berbagai sektor pembangunan lainnya.

Permasalahan mitra yang dirangkum berdasarkan hasil FGD antara lain:

1. Belum adanya diversifikasi produk ikan menjadi abon. Umumnya langsung dijual dalam bentuk segar, dijual langsung ke pasar, Selebihnya ikan dibuat ikan asin atau ikan garam.

2. Ketidakmampuan wanita nelayan desa Arakan Kabupaten Minahasa Selatan Provinsi Sulawesi Utara untuk diversifikasi dan pengolahan ikan akibat kurangnya skill dan pengetahuan menjadi salah satu penyebab daya tahan ekonomi rumah tangga nelayan rendah. Di musim paceklik, nelayan tidak akan mendapatkan penghasilan apabila tidak memiliki mata pencaharian alternative, atau melibatkan keluarga untuk menghasilkan uang guna memenuhi berbagai kebutuhan rumah tangga.

3. Wanita nelayan juga dapat bekerja dalam berbagai jenis pekerjaan Peran perempuan dapat dilibatkan dalam kegiatan ekonomi produktif. Salah satu bentuk ekonomi produktif adalah usaha pengolahan ikan seperti abon ikan, menggunakan peralatan dengan harga terjangkau.

4. Aspek produksi seperti pengemasan produk abon ikan, sehingga produk lebih saniter dan higyenis.

Berdasarkan permasalahan yang dikemukakan, diperlukan pemberdayaan terhadap wanita nelayan desa Arakan Kabupaten Minahasa Selatan Provinsi Sulawesi Utara dalam mengolah /diversifikasi produk ikan menjadi abon.

Tujuan dan Manfaat Kegiatan

Tujuan program ini yaitu memberdayakan kelompok wanita nelayan desa Arakan Kabupaten Minahasa Selatan Provinsi Sulawesi Utara dalam mengolah /diversifikasi produk ikan menjadi abon.

Adanya diversifikasi abon ikan ini diharapkan dapat meningkatan produksi olahan hasil perikanan, meningkatkan, mengembangkan SDM sehingga trampil 
dan mandiri secara ekonomi yang pada akhirnya dapat meningkatkan pendapatan keluarga nelayan.

\section{METODE PELAKSANAAN}

\section{Sasaran Kegiatan Pengabdian}

Mitra sasaran program ini adalah kelompok wanita nelayan desa Arakan Kabupaten Minahasa Selatan, secara geografis terletak di pesisir pantai dengan potensi perikanan tangkap yang potensial untuk dikembangkan

\section{Lokasi Kegiatan Pengabdian \\ Kegiatan pengabdian pada masyarakat ini dilaksanakan di desa Arakan Kecamatan Tatapaan Kabupaten Minahasa Selatan Provinsi Sulawesi Utara.}

Metode Yang Digunakan
Metode pelatihan dilakukan
berdasarkan metode pembelajaran orang dewasa (otodidak) dan dilaksanakan secara klasikal melalui diskusi kelompok secara terarah (FGD = Focus Group Discussion), penyuluhan dan pelatihan.

Penyuluhan dimaksudkan untuk merobah perilaku sumberdaya manusia (SDM) ke arah yang lebih baik dengan cara mengedukasi pengolah abon ikan dalam meningkatkan taraf kehidupan dengan usahanya sendiri, serta mengedukasi mereka untuk mengolah sumberdaya alamnya dengan bijaksana. Materi penyuluhan berisi; 1) Diversifikasi produk olahan ikan, 2) Sanitasi dan hygiene personal, 3) sarana pengolahan dan lingkungannya yang mempengaruhi mutu dan keamanan produk olahan abon ikan.

Setelah selesai materi penyuluhan, tahap selanjutnya adalah pelatihan pembuatan abon ikan. Kegiatan pelatihan dimaksud adalah praktek penerapan iptek yang terdiri dari:

a. Pengolahan /diversifikasi produk ikan menjadi abon ikan,

b. Penggunaan alat peniris minyak (spinner).

c. Pengemasan abon ikan dalam kemasan botol plastik,

d. Pengujian tingkat kesukaan oleh panelis (ibu-ibu yang mengolah abon).

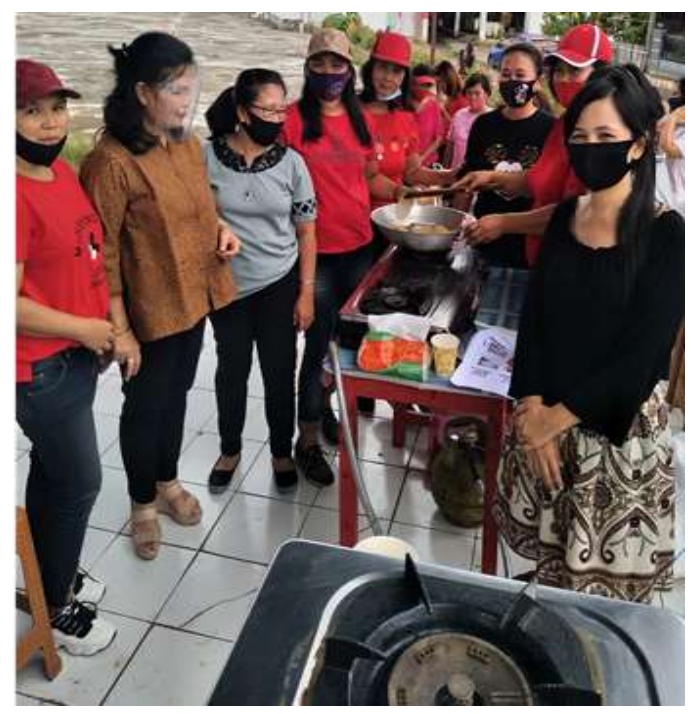

Gambar 1. Kegiatan pengolahan abon ikan

\section{HASIL DAN PEMBAHASAN}

Pemberdayaan adalah salah satu konsep didalam meningkatkan kualitas, baik kualitas sumberdaya manusia atau kualitas perekonomian. Masyarakat nelayan sebagai masyarakat yang memanfaatkan potensi laut dan pesisir laut sebagai pendapatan perekonomian tidak dapat disandingkan dengan masyarakat ekonomi disektor lain, seperti sector pertanian, sektor perindustrian dan sektor lainnya. Upaya pemberdayaan sangat diperlukan didalam mendongkrak persoalan- persoalan yang ada di masyarakat pesisir (Nelayan) sebagai upaya meningkatkan kehidupan mereka dan dapat disandingkan dengan sector perekonomian lain (Zaenal Abidin, 2017).

Pemberdayaan merupakan suatu proses dalam melakukan perubahanperubahan yang terencana. Tahapan yang dilakukan antara lain adalah penyadaran masyarakat tentang keberlangsungan hidup mereka yang bukan saja sebagai makhluk individu tetapi juga kapasitas mereka sebagai makhluk sosial, budaya dan ekonomi, sehingga selayaknya dapat berpikir lebih luas tentang dampak yang harus dihadapi ketika permasalahan terjadi. 
Kegiatan pemberdayaan kelompok wanita nelayan desa Arakan Kabupaten Minahasa Selatan diawali dengan diskusi dan penyuluhan. Materi diskusi dan penyuluhan yang disampaikan antara lain: 1) diversifikasi produk olahan ikan, 2) Sanitasi dan hygiene personal, 3) Mutu dan keamanan pangan.

Kegiatan penyuluhan ini bertujuan merobah perilaku sumberdaya manusia (SDM) ke arah yang lebih baik dengan cara memberdayakan perempuan/ibu ibu cara diversifikasi produk hasil perikanan antara lain pengolahan abon ikan.

Setelah dilakukan penyuluhan dilanjutkan dengan pelaksanaan pelatihan dan praktek pengolahan. Kegiatan pelatihan dimaksud adalah praktek penerapan iptek. Kegiatan ini dilakukan oleh tim pengabdian dibantu dengan 3 orang mahasiswa S1 tingkat akhir. Pelatihan dimaksud terdiri dari:

1. Praktek pengolahan abon ikan.

Pada sesi ini peserta pelatihan (Kelompok Gusumi) diajari cara mengolah ikan menjadi abon ikan. Pembuatan abon merupakan salah satu alternatif pengolahan ikan. Hal ini dilakukan untuk mengantisipasi kelimpahan produksi ataupun untuk penganekaragaman produk perikanan. Berdasarkan SNI 01-3707-1995, abon merupakan hasil pengolahan yang berupa pengeringan bahan baku yang telah ditambahkan bumbu-bumbu untuk meningkatkan cita rasa dan memperpanjang daya simpan. Jenis ikan yang dibuat sebagai bahan baku jenis abon belum selektif, bahkan hampir semua jenis ikan dapat dijadikan abon. Namun demikian, akan lebih baik bila dipilih jenis ikan yang mempunyai serat yang kasar dan tidak mengandung banyak duri (Rosyid, 2011).

2. Praktek penggunaan alat peniris minyak.

Penggunaan alat sederhana ini bertujuan agar kelompok mitra sasaran yaitu kelompok Gusumi mampuh menggunakan alat peniris minyak sederhana dan dapat melakukan proses produksi pengolahan abon ikan dengan waktu yang lebih singkat, sera menerapkan cara pengolahan abon ikan yang lebih bersih dan terjamin mutunya.

Pada prinsipnya kerja alat spinner atau peniris minyak adalah bahan pangan berminyak diletakkan ke dalam keranjang selanjutnya akan diputar oleh poros yang dihubungkan dengan motor listrik menggunakan $V$-Belt. Akibat dari gaya sentrifugal yang terjadi saat keranjang berputar, maka bahan akan bergerak menuju ke sisi-sisi keranjang. Bahan yang ukurannya lebih kecil daripada ukuran lubang keranjang termasuk minyak, akan bergerak keluar melewati keranjang dan jatuh di body spinner yang selanjutnya mengalir keluar dari body karena kemiringan alas body spinner. Dengan demikian, bahan yang tertinggal di dalam keranjang menjadi kering, renyah, dan siap dikemas karena kandungan minyak sudah banyak berkurang.

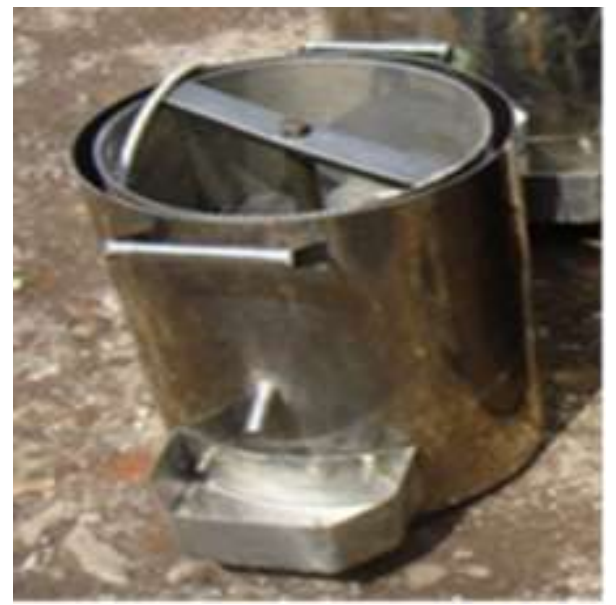

Gambar 2. Alat peniris minyak

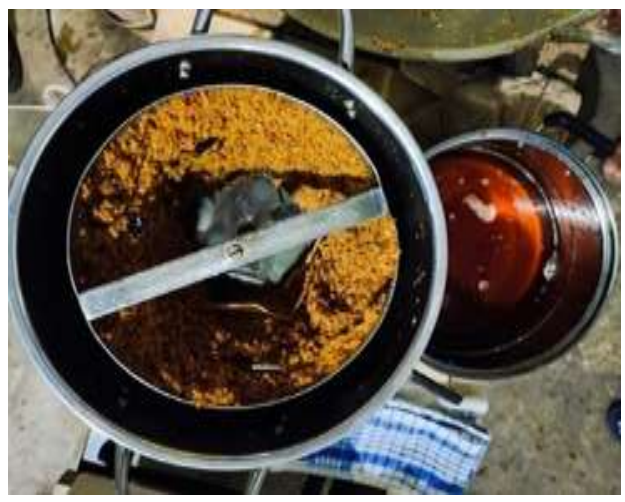




\section{Gambar 3. Penirisan minyak}

3. Setelah abon ikan selesai ditiris minyak, didingin-anginkan sebentar, dibagi menjadi dua bagian. Satu bagian disisihkan untuk dilakukan uji organoleptik (tingkat kesukaan) dan satu bagian lainnya kemudian dilanjutkan dengan praktek pengemasan. Kemasan/wadah yang digunakan adalah toples plastik kecil. Abon yang akan dikemas ditimbang terlebih dahulu sebanyak $\pm 150 \mathrm{~g}$.

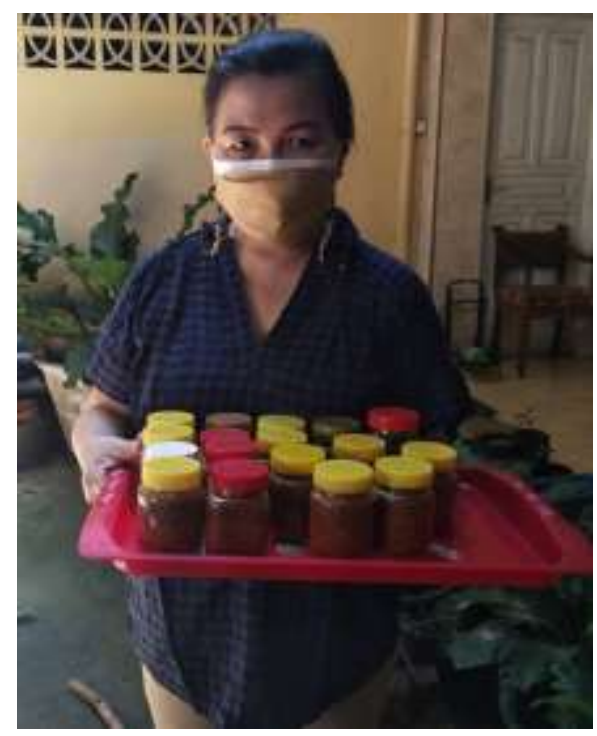

Gambar 4. Pengemasan

Tahap selanjutnya adalah praktek penilaian organoleptik berdasarkan tingkat kesukaan suka, suka, agak tidak suka dan tidak suka. Panelis diminta untuk mencentang atribut penilaian sesuai dengan tingkatan atau level yang mereka sukai. Atribut yang dinilai yaitu rasa, tekstur, aroma dan kenampakan abon ikan. Hasil penilaian panelis adalah sebagai berikut:

\section{a. Rasa}

Dari 15 orang panelis rata-rata memberikan respon sangat suka terhadap rasa abon ikan. Rasa merupakan faktor yang penting dalam menentukan penerimaan atau penolakan konsumen terhadap suatu bahan pangan. Meskipun tekstur bahan pangan baik namun jika rasanya tidak enak maka konsumen akan menolak produk tersebut (Winarno, 2004). Menurut Soekarto (1985), rasa makanan yang kita kenal sehari-hari sebenarnya bukanlah satu tanggapan, melainkan campuran dari tanggapan cicip, bau, dan trigeminal yang diramu oleh kesan kesan lain seperti penglihatan, sentuhan, dan pendengaran. Jadi, kalau kita menikmati atau merasakan makanan, sebenarnya kenikmatan tersebut diwujudkan bersama-sama oleh kelima indera. Peramuan rasa itu ialah suatu sugesti kejiwaan terhadap makanan yang menentukan nilai pemuasan orang yang memakannya.

b. Tekstur

Untuk nilai tekstur panelis juga rata-rata memberikan nilai sangat suka yaitu sebanyak 11 orang. 4 orang panelis lainnya memberikan nilai suka. Penilaian tekstur abon ikan penting dilakukan karena merupakan salah satu ciri yang membedakannya dengan abon berbahan baku lainnya.

c. Aroma

Aziz dan Vui (2012), menyatakan bahwa aroma adalah salah satu komponen cita rasa yang sangat berpengaruh pada makanan. Aroma merupakan hasil dari respon indra penciuman akibat dari menguapnya senyawa tertentu yang sedikit larut lemak dan direspon dengan baik oleh indra penciuman dan dikenali oleh sistem tubuh sebagai aroma tertentu. Penilaian panelis terhadap aroma abon ikan rata-rata memberikan nilai yang amat sangat suka, yakni sebanyak 13 orang, 2 orang panelis lainnya memberikan penilaian suka terhadap aroma abon ikan (Huthaimah et al, 2017).

d. Kenampakan; Nilai kenampakan juga memberikan hasil yang hamper sama dengan aroma. Sebanyak 13 orang panelis memberikan nilai amat sangat suka. Kenampakan dipengaruhi oleh beberapa faktor diantaranya adalah proses penggorengan. Proses pengorengan menghasilkan warna kuning kecoklatan. Adapun warna 
kecolatan yang ditimbulkan disebabkan adanya proses karamelisasi.

Karamel adalah substansi berasa manis, berwarna coklat dan merupakan campuran dari beberapa senyawa yang mirip karbohidrat. Sukrosa akan mengalami karamelisasi apabila suhu yang digunakan di atas titik lebur sukrosa. Reaksi maillard adalah reaksi karbohidrat, khususnya gula pereduksi dan gugus amina primer. Hasil reaksi tersebut menghasilkan bahan berwarna coklat yang dikehendaki atau kadang juga menjadi pertanda penurunaan mutu (Kasmiati et al, 2020)

Uji organoleptik untuk mengetahui tingkat kesukaan konsumen terhadap abon ikan layang dilakukan di lokasi pelaksanaan PKM.

Secara keseluruhan, untuk uji organoleptik untuk mengetahui tingkat kesukaan panelis rata-rata penilaian adalah amat sangat suka dan sangat suka terhadap produk abon ikan yang dihasilkan. Panelis terdiri dari anggota kelompok Gusumi, mahsiswa tingkat akhir yang terlibat langsung dalam kegiatan dan beberapa warga sekitar.

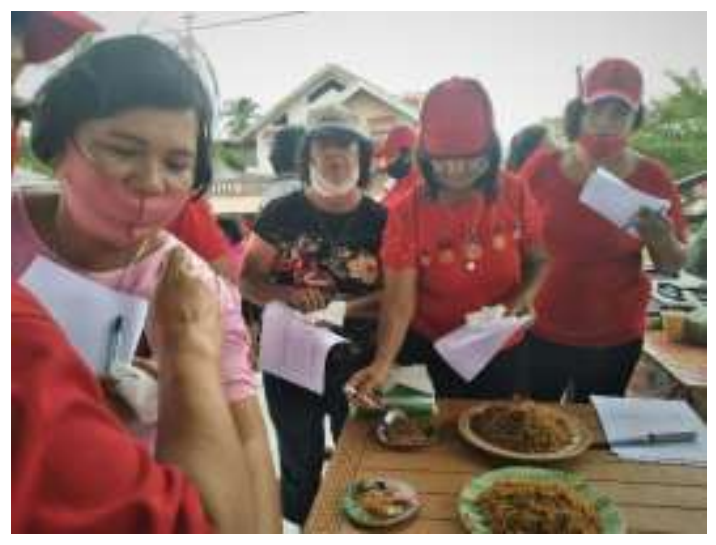

Gambar 5. Pengujian organoleptik oleh peserta pelatihan

Produk abon ikan yang dihasilkan oleh kelompok Gusumi yang merupakan perwakilan dari kelompok wanita nelayan yang ada di desa Arakan Kabupaten Minahasa Selatan, telah diuji laboratorium untuk parameter uji ALT (Angka Lempeng Total), Kadar Air, dan kadar lemak..
Abon ikan yang dihasilkan pada produksi skala rumah tangga dari kelompok Gusumi memiliki karakteristik mutu sebagai berikut ALT $2.1 \times 10^{2} \mathrm{CFU} / \mathrm{g}$, Kadar Air 3.40 - 4.5\%, Kadar Lemak 25 $32.34 \%$.

\section{KESIMPULAN DAN SARAN}

\section{Kesimpulan}

Pemberdayaan kaum perempuan melalui edukasi diversifikasi produk hasil perikanan merupakan salah satu alternatif pengembangan matapencaharian berbasis teknologi tepat guna. Hal ini merupakan tuntutan dan kebutuhan yang harus dilakukan, khususnya untuk masyarakat pesisir. Upaya ini memiliki relevansi dengan penanganan kemiskinan.

Pemanfaatan teknologi dan
peralatan tepat guna dalam
pengembangan mata pencaharian alternatif merupakan sarana untuk menunjang optimalisasi aktivitas usaha dan menjamin agar peluang kerja di kawasan pesisir tetap tersedia bagi mereka yang membutuhkan. Struktur sosial dan struktur ekonomi daerah pesisir memberi ruang yang luas bagi perempuan pesisir untuk mengembangkan mata pencaharian alternatif.

\section{Saran}

Program pemberdayaan masyarakat pesisir ini seyogyanya menjadi perhatian serius. Partisipasi perguruan tinggi, korporasi, dan pihak-pihak terkait lainnya diperlukan dalam mengembangkan teknologi tepat guna yang efektif untuk mengelola potensi sumberdaya pesisir-laut sebagai basis kegiatan ekonomi yang diarahkan akan menjadi matapencaharian alternatif bagi perempuan pesisir.

\section{DAFTAR PUSTAKA}

Abdul Aziz, Y. \& Vui, C. N. (2012). The role of Halal awareness and Halal certification in influencing non-Muslim"s purchasing intention. Paper presented at $3 \mathrm{rd}$ International 
Conference on Business and Economic Research (3rd ICBER 2012) Proceeding, 1819-1830.

Dewayanti, Ratih dan Erna Ermawati Chotim. 2004. Marjinalisasi dan Eksploitasi Perempuan Usaha Mikro di Pedesaan Jawa. Bandung: Yayasan Akatiga.

Hikmat, 2004. Strategi Pemberdayaan Masyarakat. Bandung (ID): Humaniora utama.

Huthaimah Huthaimah, Yusriana Yusriana, Martunis Martunis. 2017. Pengaruh Jenis Ikan dan Metode Pembuatan Abon Ikan terhadap Karakteristik Mutu dan Tingkat Penerimaan Konsumen. Jurnal IImiah Mahasiswa Vol 2, No.3. http://jim.unsyiah.ac.id/JFP/issue/vie w/183

Ismail A.M., Dhanang E. P., 2017. Inovasi Pembuatan Abon Ikan Cakalang Dengan Penambahan Jantung Pisang Agritech : Vol. XIXNo. 1 Juni 2017: 45-54, ISSN: 1411-1063. Jember;

https://media.neliti.com/media/public ations/217400-inovasi-pembuatanabon-ikan-cakalang-den.pdf

Kasmiati, Nurfitri Ekantari, Asnani, Suadi, Amir Husni. 2020 Mutu Dan Tingkat Kesukaan Konsumen Terhadap Abon Ikan Layang (Decapterus sp.). JPHPI 2020, Volume 23 Nomor 3. Journal.ipb.ac.id/index.php/jphpi. https://www.google.com/url?sa=t\&rct $=\mathrm{j} \& \mathrm{q}=\&$ esrc $=\mathrm{s} \&$ source $=$ web $\& \mathrm{~cd}=\& \mathrm{ve}$ $\mathrm{d}=2$ ahUKEwiD7a3H3p30AhVOfXOK HX4OCeAQFnoECAUQAw\&url=http s\%3A\%2F\%2Fjournal.ipb.ac.id\%2Fi ndex.php\%2Fjphpi\%2Farticle\%2Fvie w\%2F32700\%2F20847\&usg=AOvV aw1kbl0741 LJeS-4AFtpz470

[LPM Unsrat] Lembaga Pengabdian kepada Masyarakat. 2019. Kinerja Lembaga Pengabdian kepada Masyarakat Universitas Sam Ratulangi Manado.

Rosyid Meica Chandrianto. 2011. Pengendalian Mutu Proses Pembuatan Abon Lele di IRT Karmina. UNS-F. Pertanian Prog. Teknologi Hasil Pertanian. https://digilib.uns.ac.id/dokumen/det ail/19842/Pengendalian-MutuProses-Pembuatan-Abon-Lele-diIRT-Karmina.

Zaenal Abidin, AS . 2017. Pemberdayaan Masyarakat Nelayan Di Pesisir Pantai Blanakan Kabupaten Subang. http://fisip.unjani.ac.id/wpcontent/uploads/2019/04/pemberday aan-masyarakat-nelayan-di-pesisirpantai-blanakan-kabupatensubang.pdf

Soekarto, S.T.1985. Penilaian Organoleptik (untuk Industri Pangan dan Hasil Pertanian). Penerbit Bharata Karya Aksara, Jakarta.

Winarno, F.G. 2004. Kimia Pangan dan Gizi. Gramedia Pustaka Utama. Jakarta. 